\title{
Acute Coronary Syndrome in a Patient with a Single Coronary Artery
} Juergen Kammler ${ }^{1 *}$, Blessberger Hermann ${ }^{1}$, Alex Kypta ${ }^{1}$, Michael Lichtenauer ${ }^{2}$, Alexander Nahler ${ }^{1}$, Lambert Thomas ${ }^{1}$ and Steinwender Clemens $^{1}$

${ }^{1}$ Linz General Hospital, 1st Medical Department - Cardiology, Johannes Kepler University School of Medicine, Linz, Austria ${ }^{2}$ Department of Internal Medicine II, Paracelsus Medical University Salzburg, Salzburg, Austria

\begin{abstract}
Coronary anomalies are rare congenital abnormalities and are often associated with complex congenital heart diseases and manifest in infancy or childhood. Single coronary artery arising from the sinus of Valsalva supplying the entire heart is one of these congenital anomalies. The prevalence is reported to be approximately 0.3 to $2.0 \%$ of the general population, mostly clinically asymptomatic and with good prognosis. However, in some cases this anomaly can present as acute coronary syndrome in adults. Literature reports of patients with both a single coronary artery and an acute coronary syndrome are sparse, and percutaneous coronary interventions in such cases are technically challenging. We report a case of a patient with a single coronary artery suffering from an acute coronary syndrom who underwent complex bifurcational percutaneous intervention and provide a review of the literature.
\end{abstract}

Keywords: Coronary anomalies; Congenital heart diseases; Single coronary artery

\section{Case Report}

We present a 70 years old male patient with an acute coronary syndrom transferred to our institution for angiography. The patient's cardiac history was uneventful until the date of admission in the referring hospital. The troponin I level was elevated (troponin I 0.141 $\mathrm{ng} / \mathrm{ml}$ - upper limit of normal $0.05 \mathrm{ng} / \mathrm{ml}$ ), CK and CK-MB were within normal ranges as were the other lab parameters. The ECG at admission showed only discrete unspecific changes of the repolarisation.

Coronary angiography revealed a single coronary artery (SCA) originating from the left coronary sinus with

significant stenoses of the circumflex artery as well as the right coronary artery (Figure $1 \mathrm{a}$ and $\mathrm{lb}$ ).

The coronary anomaly was assumed to be a benign type of SCA because no evidence of proximal right coronary artery compression driven by an interarterial course between the pulmonary artery and the aorta was found. Therefore, an ad hoc percutaneous coronary intervention (PCI) was performed.

Both stenoses were treated with zotarolimus eluting stents (Resolute Integrity", Medtronic, MA, USA) via a 7 french 3.5 Launcher $\mathrm{EBU}^{\circ}$ catheter (Medtronic, MA, USA) (Figure 1c and 1d).

The circumflex artery was revacularized applying a two stent strategy (mini-crush technique). After predilatation and stenting of the distal circumflex artery $(3.0 \times 22 \mathrm{~mm})$, a mini-crush was performed between the obtuse marginal branch and the distal circumflex artery $(3.0 \times 22 \mathrm{~mm}$ and $2.25 \times 22 \mathrm{~mm})$. The final step of the procedure comprised a kissing balloon maneuver. The right coronary artery was revascularized after predilatation using a $2.25 \times 26 \mathrm{~mm}$ drug eluting stent. The post-interventional course was uneventful.

After this a computed tomography of the heart confirmed that the right coronary artery indeed originated from the left main coronary artery following a retro-aortic course (Figure 1e and 1f).

\section{Discussion}

Coronary anomalies are uncommon angiographic findings. The etiology is uncertain. Among these anomalies, isolated SCAs are one of the rarest congenital anomalies (0.02-0.07\% of all patients undergoing coronary angiography), especially if originating from the left coronary sinus [1-4]. In these patients, the single coronary artery arises from the aortic trunk through a single ostium and supplies the entire heart. Yamanaka and Hobbs modified the previous model of Lipton et al. [5] and thereby created the current classification [6]: There are four

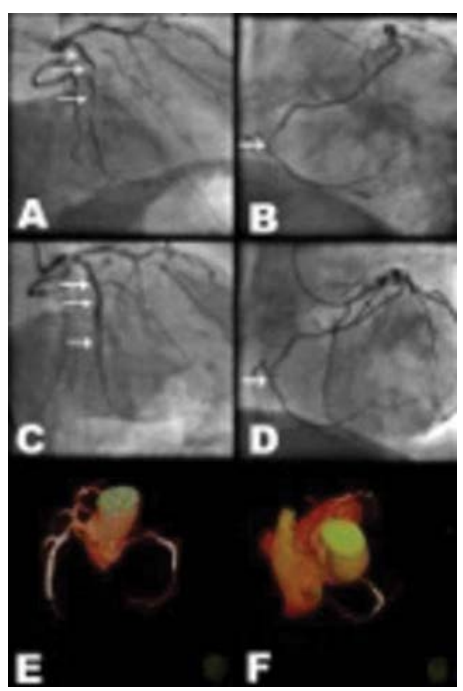

Figure 1: (a) Coronary angiogram in RAO projection showing significant stenoses of the circumflex artery (distal circumflex and obtuse marginal branch, white arrows). (b) Coronary angiogram in LAO projection showing a significant stenosis of the right coronary artery (white arrow). (c) Circumflex artery after coronary intervention (RAO projection). (d) Right coronary artery after coronary intervention (LAO projection). (e and f) Computed tomography showing the single coronary artery after coronary intervention. The right coronary artery originates from the left main stem and travels to the right side on a retro-aortic course.

*Corresponding author: Juergen Kammler, Linz General Hospital, 1st Medical Department - Cardiology Johannes Kepler University School of Medicine, Linz, Austria, Krankenhausstrasse 9, A-4021 Linz; Austria, Tel: +43-732-7806-6220; E-mail: juergen.kammler@akh.linz.at

Received December 23, 2015; Accepted January 07, 2016; Published January 11, 2016

Citation: Kammler J, Hermann B, Kypta A, Lichtenauer M, Nahler A, et al. (2016) Acute Coronary Syndrome in a Patient with a Single Coronary Artery. J Clin Case Rep 6: 695. doi:10.4172/2165-7920.1000695

Copyright: (c) 2016 Kammler J, et al. This is an open-access article distributed under the terms of the Creative Commons Attribution License, which permits unrestricted use, distribution, and reproduction in any medium, provided the original author and source are credited. 
different ways the right coronary artery can use to travel from the right to left side: Firstly an anterior course anterior to the pulmonary trunk, secondly an inter-arterial course between pulmonary artery and aorta, thirdly a septal course through the interventricular septum and finally a retro-aortic course between the aortic root and the left atrium $[7,8]$. As mentioned above, the inter-arterial course is the most malignant that is strongly associated with sudden death, myocardial ischemia or congestive heart failure being caused by a compression of the origin of the right coronary artery between the pulmonary trunk and the aorta.

Besides coronary angiography, multi-slice detector computed tomography improved visualization of coronary anomalies [9]. This technique helps to determine the course the vessels take, which is important for prognosis and revascularization procedures as mentioned above. Literature reports of patients with both a single coronary artery and an acute coronary syndrome are sparse, and percutaneous coronary interventions in such cases are technically challenging [10-13]. Importantly, you have to keep in mind that the risks associated with a percutaneous intervention of a SCA is similar to that of an unprotected left main stem because dissection of the ostium by the guiding catheter in a patient with SCA can be life threatening or lethal. In these cases it is very important that the guiding catheter is well chosen and that the guide corresponds to the sinus of origin rather than the artery to be treated. In our case the peri-interventional course was uneventful and the patient left hospital two days after the procedure on dual antiplatelet therapy.

\section{Conclusion}

We report a successful complex coronary intervention performed simultaneously in two vessels via one guiding catheter in a patient with a single coronary artery. There are several points that have to be taken into account when treating patients with this kind of coronary anomaly. An interventional cardiologist has to be familiar with the different anatomical types of this congenital anomaly and to be aware of the increased peri-procedural complication risk.

\section{References}

1. Kaku B, Shimizu M, Yoshio H, Ino H, Mizuno S, et al. (1996) Clinical features of prognosis of Japanese patients with anomalous origin of the coronary artery. Jpn Circ J 60: 731-41.

2. Garg N, Tewari S, Kapoor A, Gupta DK, Sinha N (2000) Primary congenital anomalies of the coronary arteries: a coronary: arteriographic study. Int J Cardiol 74: 39-46.

3. Fujimoto S, Kondo T, Orihara T, Sugiyama J, Kondo M, et al. (2011) Prevalence of anomalous origin of coronary artery detected by multi-detector computed tomography at one center. J Cardio 57: 69-76

4. Angelini P, Velasco JA, Flamm S (2002) Coronary anomalies: incidence, pathophysiology, and clinical relevance. Circulation 105: 2449-2454.

5. Lipton MJ, Barry WH, Obrez I, Silverman JF, Wexler L (1979) Isolated single coronary artery: diagnosis, angiographic classification, and clinical significance. Radiology 130: 39-47.

6. Yamanaka O, Hobbs RE (1990) Coronary artery anomalies in 126,595 patients undergoing coronary arteriography. Cathet Cardiovasc Diagn 21: 28-40.

7. Kim SY, Seo JB, Do KH, Heo JN, Lee JS (2006) Coronary anomalies: classification and ECG-gated multi- detector row CT findings with angiographic correlation Radiographics 26: 317-334.

8. Yuksel S, Meric M, Soylu K, Gulel O, Zengin H, et al. (2013) The primary anomalies of coronary artery origin and course: A coronary angiographic analysis of 16,573 patients. Exp Clin Cardiol 18: 121-123.

9. Tariq R, Kureshi SB, Siddiqui UT, Ahmed R (2012) Congenital anomalies of coronary arteries: Diagnosis with 64 slice multidetector CT. Eur J Radiol 81: 1790-1797.

10. Dai J, Katoh O, Kyo E, Zhou XJ (2014) Percutaneous intervention in a patient with a rare single coronary artery from the left coronary sinus of valsava. J Res Med Sc 19: 375-377.

11. Nasir JM, Hawkins K, Patino G, Furgerson J, Soh EK (2012) Anterior STsegment elevation myocardial infarction in a patient with an L-I type single coronary artery. JACC Cardiovasc Interv 5: e9-10.

12. Williams PD, Bury RW, Brack MJ (2009) Emergency percutaneous coronary intervention in the setting of a single left coronary ostium. Circ Cardiovasc Interv 2: 149-51.

13. Mahapatro AK, Patro AS, Sujatha V, Sinha SC (2014) Isolated single coronary artery presenting as acute coronary syndrome: case report and review. Int J Angiol 23(2): 143-6. 